\title{
Tissue- and Age-Specific Expression Patterns of Alternatively Spliced Agrin mRNA Transcripts in Embryonic Rat Suggest Novel Developmental Roles
}

\author{
Donna M. Stone and Karoly Nikolics \\ Department of Neuroscience, Genentech, Inc., South San Francisco, California 94080
}

Agrin is an extracellular matrix protein that mediates the nerve-induced clustering of nicotinic acetylcholine receptors on target muscle cells, and thus plays a key role in development of the neuromuscular synapse. Alternative exon usage within the rat agrin gene predicts numerous protein isoforms, which differ by the inclusion or exclusion of small inserts at three sites in the C-terminal half of the molecule; the insert status at two of these sites, termed $Y$ and $Z$, profoundly influences the acetylcholine receptor clustering activity. We have examined the cellular expression patterns of agrin messenger RNA transcripts during rat embryogenesls by in situ hybridization with isoformspecific probes. Six 36-mer oligonucleotide probes were designed to distinguish between mRNA isoforms at either the $Y$ site: the encoded protein contains either no insert (Yo) or a 4-amino acid insert (Y4), or the $Z$ site: the encoded protein contains either no insert or one of 8 (Z8), 11 (Z11), or 19 (Z19) amino acids. Strikingly different expression patterns were observed for the individual Y- and Z-site encoding messages. While optional exon usage predicts the posslbillty of elght different agrin isoforms at the two splice sites, we detected only four isoforms in vivo: Y4Z0, Y0Z0, Y4Z8, and Y4Z19. The Y4Z0 transcript, which comprised the majority of the agrin expressed, was localized exclusively to nervous tissue and exhibited a distribution profile suggestive of a potential role in neurogenesis and/or neural differentiation. From embryonic day 13 to birth, Y4Z0 was found in mitotic ventricular zones, spinal, cranial, and sympathetic ganglia, and diffusely throughout the brain. In contrast, YOZO was not expressed in neurons, but specifically labeled capillary endothelial cells within the developing nervous system. Y4Z8 and Y4Z19, the forms most active in acetylcholine receptor aggregation, were expressed at low levels only in spinal and brainstem motor neurons; Z19 expression declined from embryonic day 15 to adulthood, whereas $\mathbf{Z 8}$ expression increased slightly during this period. Transcripts encoding the $\mathrm{Z11}$ insert could not be detected. These data suggest potential novel

\footnotetext{
Received May 15, 1995; accepted June 12, 1995.

We are grateful to Richard Scheller for providing the rat agrin cDNAs, to Peter Seeburg for helpful discussions on the in situ hybridization protocol, and to Heidi Phillips and Mark Armanini for technical and interpretive advice.

Correspondence should be addressed to Karoly Nikolics, Department of Neuroscience, Genentech, Inc., Mailstop 72, 460 Point San Bruno Boulevard, South San Francisco, CA 94080.

Copyright (C) 1995 Society for Neuroscience $0270-6474 / 95 / 156767-12 \$ 05.00 / 0$
}

biological roles for agrin beyond that originally proposed in synapse formation.

[Key words: agrin, in situ hybridization, alternatively spliced, neuronal-specific, protein isoforms, extracellular matrix]

Alternative splicing of nuclear precursor RNAs (pre-mRNAs) represents an important control point in the regulation of eukaryotic gene expression. Differential splice site selection within a primary RNA transcript can yield multiple protein isoforms, often with differing activities or functions. The expression patterns of these isoforms can vary within different cell types and at different stages of development (see Breitbart et al., 1987; Smith ct al., 1989, for revicw). While the factors involved in regulation of splice site selection are poorly understood, alternative exon usage appears to be a common mechanism for generating protein isoform diversity from genes coding for extracellular matrix-associated proteins (Boyd et al., 1993).

Agrin, which encodes several isoforms of a large multidomain protein localized to extracellular matrix, represents one example of a gene subject to complex regulated alternative splicing. Agrin was initially isolated and purified from the electric organ of the marine ray Torpedo californica based on its ability to induce aggregation of nicotinic acetylcholine receptors (AChR) in muscle cell membranes (Nitkin et al., 1987); as such, it was hypothesized to represent the motor neuron-derived signal that initiates neuromuscular synapse formation (McMahan, 1990; Hall and Sanes, 1993). Consistent with this interpretation, cells transfected with agrin cDNA express agrin on their extracellular surface and, when cocultured with primary muscle fibers, inducc clustering of AChRs at sites of cell contact (Campanelli et al., 1994). Agrin is synthesized within spinal cord motor neurons at the time of initial synapse formation (Rupp et al., 1991; Smith et al., 1992; Tsim et al., 1992) and transported down the motor neuron axon (Magill-Solc and McMahan, 1990); moreover, antiagrin antibodies can inhibit the formation of AChR clusters at developing neuromuscular contacts in culture (Reist et al., 1992). Subsequent to receptor clustering, agrin induces at this site the accumulation of several other molecules important in the multistep process of synapse maturation, such as acetylcholinesterase, laminin, and heparan sulfate proteoglycan (Wallace, 1989; Nitkin and Rothschild, 1990).

Cloning of agrin cDNAs from rat (Rupp et al., 1991) and chick (Tsim et al., 1992) and a homology search of the predicted amino acid sequences, revealed agrin to be a complex protein with a predicted molecular weight of $\sim 205 \mathrm{kDa}$, containing several sequence motifs common to other extracellular matrix and 


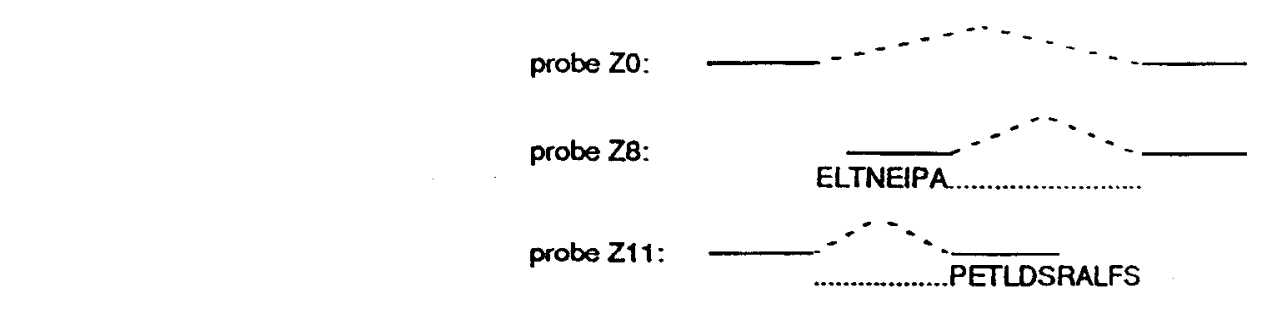

Figure 1. Modular organization of the rat agrin protein and location of oligonucleotide probes for Y- and Z-site isoforms. Protein modules of agrin are represented by boxes; accepted amino acid inserts are shown below or above corresponding $\mathrm{Y}$ or $\mathrm{Z}$ alternative splice sites, respectively. Probes were complementary to messenger RNA sequences encoding the indicated amino acid stretches (solid lines). Dashed lines represent a direct connection between the $5^{\prime}$ and $3^{\prime}$ encompassing probe sequences. $S S$, signal sequence.

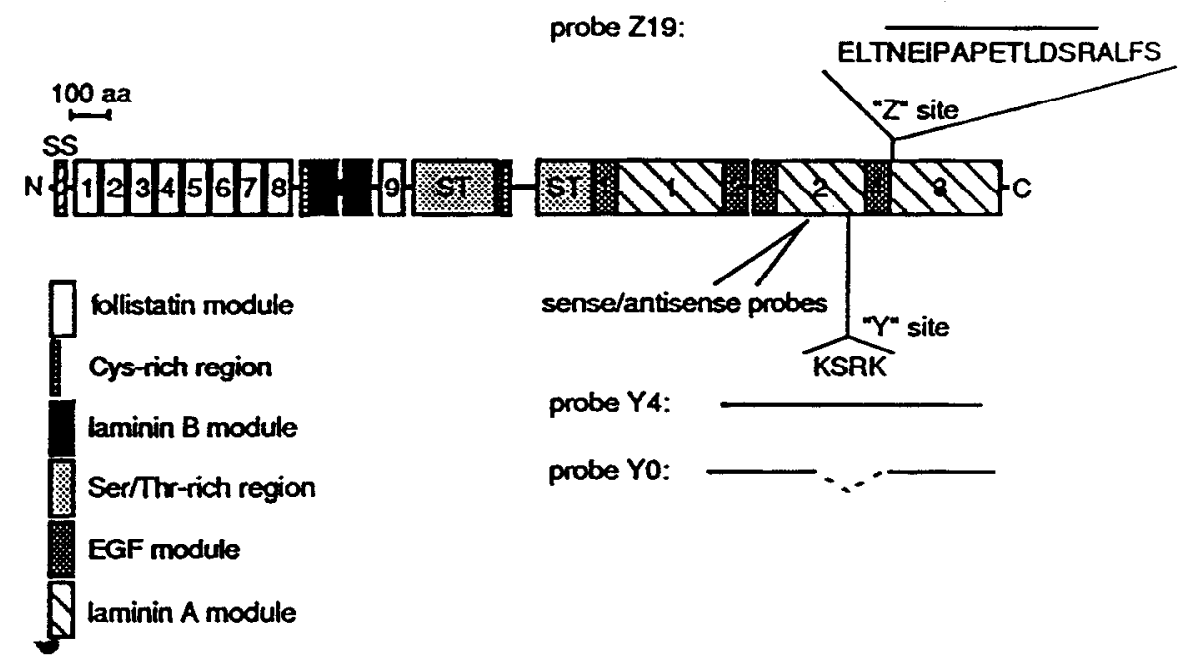

secreted proteins. Thus, agrin can be divided roughly into three regions: the $\mathrm{N}$-terminal portion, which contains nine follistatinlike modules preceded by a putative secretory signal sequence and interrupted by a laminin B-homologous domain between the eighth and ninth follistatin repeats; the middle portion, rich in serine, threonine, and proline; and the C-terminal portion containing four EGF domains interspersed with three laminin A-homologous modules (Rupp et al., 1992; Patthy and Nikolics, 1993, 1994). Based on cDNA sequence analysis, several protein isoforms of agrin are predicted; isoform diversity results from the inclusion or exclusion by alternative splicing of multiple small exons at the $3^{\prime}$ end of the mRNA coding region. In the chick protein, these sites have been termed the A and B sites, and reside at amino acid positions 1610 and 1746 (Tsim et al., 1992), respectively. In rat agrin, the corresponding sites (termed $\mathrm{Y}$ and $\mathrm{Z}$ ) are located, respectively, at amino acid positions 1710 and 1779; an additional insert site (the $\mathrm{X}$ site) was identified at position 1144 (Rupp et al., 1991; Ferns et al., 1992; Hoch et al., 1993). The $X$ site can contain either no insert or a 3- or 12amino acid insert, the $Y$ site either no insert or a 4-amino acid insert, and the $Z$ site either no insert, or one of $8-, 11-$, or 19 $(8+11)$ amino acids; each insert is encoded on a separate exon in the corresponding mouse gene (Rupp et al., 1992).

Recent experiments with recombinant agrin have shown that not all isoforms induce $\mathrm{AChR}$ clustering to a similar extent (Ferns et al., 1992, 1993; Ruegg et al., 1992; Daggett et al., 1994). Thus, striking differences were observed in the clustering activity mediated by the different $\mathrm{Z}$-site isoforms on muscle cells in vitro, lesser differences were found for $\mathrm{Y}$-site isoforms, and no differences in activity were observed for $\mathrm{X}$-site variants (Ferns et al., 1993). Whereas all isoforms were active on C2 mouse myotubes, those containing inserts at the $\mathrm{Y}$ - and $\mathrm{Z}$-splice sites were more active than the form lacking inserts; Y4Z8 was the most active isoform.

In initial attempts to understand the regulation of agrin during development, pan-specific agrin probes were used to examine the distribution of agrin mRNA, both by Northern analysis and by in situ hybridization (Tsim et al., 1992; Biroc et al., 1993; Hoch et al., 1993; Thomas et al., 1993; Ma et al., 1994; O'Connor et al., 1994). Additionally, PCR analyses defined tissue- and age-specific expression patterns of differentially spliced agrin mRNA transcripts (Ruegg et al., 1992; Hoch et al., 1993; Thomas et al., 1993). However, these studies have not allowed for the direct localization of individual mRNA variants at the cellular level. By in situ hybridization with isoform-specific probes we have previously characterized the cell-specific distribution of chick agrin mRNAs in developing spinal cord (Honig et al., 1993). In the present study we have focused on mammalian development, and demonstrate a more comprehensive analysis of the cell type-and age-specific expression patterns of alternatively spliced agrin transcripts in the developing rat nervous system. The observed unique and distinct distribution patterns of mRNA transcripts suggest potential novel developmental roles for agrin variants, beyond that previously recognized in synaptogenesis.

\section{Materials and Methods}

In situ hybridization. Timed pregnant female Sprague-Dawley rats were obtained from Charles River Laboratories (Wilmington, MA). To obtain fetal tissues prior to embryonic day 20 (E20), mothers were killed by $\mathrm{CO}_{2}$ inhalation followed by decapitation, and embryos were removed and placed in $4 \%$ paraformaldehyde (PF) in $0.1 \mathrm{M}$ phosphate buffer, $\mathrm{pH}$ 7.2 , at $4^{\circ} \mathrm{C}$ from $4 \mathrm{hr}$ over night. To obtain tissues from developmentally older animals, rats were anesthetized on ice (postnatal day $1 ; \mathrm{P} 1$ ) or with sodium pentobarbital (P7-adult), and perfused transcardially with $4 \% \mathrm{PF}$ in phosphate buffer. Brains and spinal cords were removed and postfixed in perfusate for 1-2 hr. Tissues were washed in phosphatebuffered saline (PBS), cryoprotected in $20 \%$ sucrose in PBS at $4^{\circ} \mathrm{C}$ for 24-48 hr, embedded in Tissue Tech O.C.T compound (Miles Inc., Elkhart, IN) and frozen at $-70^{\circ} \mathrm{C}$. Sections $16 \mu \mathrm{m}$ thick were cut on a cryostat, thaw mounted onto Superfrost Plus glass slides (Baxter, Deerfield, IL), and allowed to dry for $30 \mathrm{~min}$ to $1 \mathrm{hr}$ at room temperature, then at $42^{\circ} \mathrm{C}$ for $20 \mathrm{~min}$. Slide-mounted sections were placed in $4 \% \mathrm{PF}$ in phosphate buffer for $5 \mathrm{~min}$ at $4^{\circ} \mathrm{C}$, washed twice in PBS, then de- 


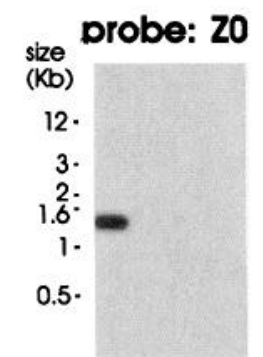

CDNA: 0 i 8 iो Yo

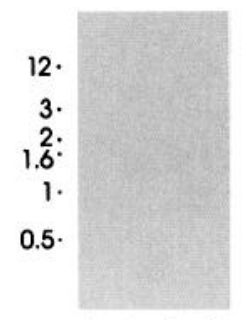

$\begin{array}{llll}0 & 8 & 11 & 19\end{array}$
$\mathbf{Z 8}$

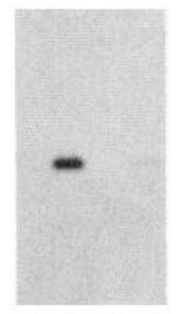

0 8 iा Y4

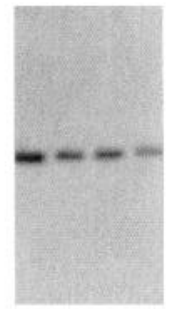

$0 \quad 8 \quad 1119$
211

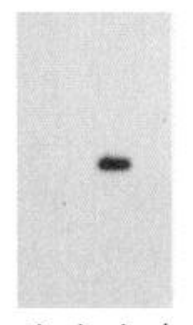

$0 \quad 81119$ antisense

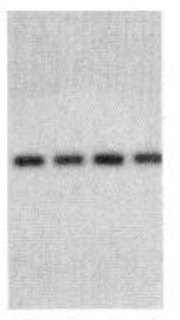

o 8 iो
$\mathbf{Z 1 9}$

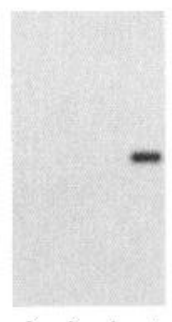

0 8 iा 19

sense

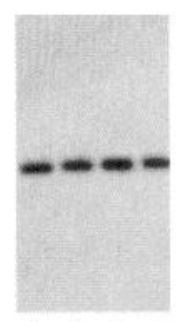

o 8 iो

Figure 2. Specificity of rat agrin isoform probes. Eight identical Southern blots, each containing four rat agrin cDNA variants, were hybridized separately to the eight rat agrin oligonucleotide probes. Probes were tailed with $\alpha-\left[{ }^{32} \mathrm{P}\right]-\mathrm{dATP}$, and hybridization and washing conditions were similar to those used for in situ hybridization. From left to right, the four lanes in each blot contain size-separated EcoRVHind III-digested fragments of Y4Z0 (0), Y4Z8 (8), Y4Z11 (11), and Y4Z19 (19) cDNAs, respectively. The individual probes are shown above the blots to which they were hybridized. The $1.4 \mathrm{~kb}$ fragment represents bases \#4446-5878 of the rat agrin cDNA.

hydrated in $70 \%$ and $95 \%$ ethanol, sequentially. Slides were stored at $4^{\circ} \mathrm{C}$ in $95 \%$ ethanol until required.

Six 36-mer oligonucleotides were designed to recognize specifically the six different splice variants at the $\mathrm{Y}$ and $\mathrm{Z}$ sites. Additionally, one pan-specific 36-mer oligonucleotide, designated "antisense," was designed to hybridize to all splice variants, and its reverse complement, "sense," was designed as a negative control probe. Probes are identified by a letter followed by a number, representing the splice site and the encoded amino acid insert size, respectively. The probe sequences were: Y0 (beginning at nucleotide 5110; Rupp et al., 1991), 5'-GAGCATGGTGTGCGGAACCGGAGATTCCCCTAGCAC-3'; Y4, 5'-GGTGTGCGGAACCTTGCGGGATTTCGGAGATTCCCC-3'; Z0 (beginning at nucleotide 5520), 5'-CTCTGCAGTGCCTTCTCACTCTCAATCACAGCATTG-3'; Z8, 5' -CTCTGCAGTGCCTTCTCGGCTGGGATCTCATTGGTC-3'; Z11, 5'-GAATCCAGAGTTTCAGGACTCTCAATCACAGCATTG-3'; Z19, 5'-GGAATCCAGAGTTTCAGGGGCTGGGATCTCATTGGT-3'; antisense (nucleotides 4895-4390), 5'-CATCTGTCTTCTGCCCATTGTAGAGGAGTAAGCCAC-3'; sense, 5'-GTGGCTTACTCCTCTACAATGGGCAGAAGACAGATG-3' ' Oligonucleotides were labeled with $\alpha{ }^{-35} \mathrm{~S}$-dATP $(>1000 \mathrm{Ci} / \mathrm{mmol}$; Amersham Corp., Arlington Heights, IL) and terminal transferase (BoehringerMannheim, Indianapolis, IN), to a specific activity of $1 \times 10^{7} \mathrm{cpm} / \mu \mathrm{g}$. Probes were purified on Bio-Spin 6 columns (Bio-Rad Laboratories, Richmond, CA).

The in situ hybridization protocol was carried out essentially as described by Wisden and Morris (1994). Immediately prior to hybridization, slides were removed from ethanol and air dried. Labeled probe was added in hybridization buffer $\left(\sim 3 \times 10^{5} \mathrm{cpm} / 100 \mu\right.$ l hybridization buffer per slide), sections were covered with parafilm coverslips, and slides incubated horizontally in a humid chamber (saturated with $50 \%$ formamide, $4 \times \mathrm{SSC}$ ) over night at $52^{\circ} \mathrm{C}$ (for $\mathrm{Y0}$ and $\mathrm{Y} 4$ probes) or $42^{\circ} \mathrm{C}$ (all other probes). Hybridization buffer was $50 \%$ formamide, $4 \times$ SSC, $10 \%$ dextran sulfate, $5 \times$ Denhardt's $(50 \times$ Denhardt's is: $1 \%$ each (w/v) Ficoll, polyvinylpyrrolidone, and bovine serum albumin), $200 \mu \mathrm{g} /$ ml sonicated salmon sperm DNA, $100 \mu \mathrm{g} / \mathrm{ml}$ polyadenylic acid (Sigma Chemical Co.), $25 \mathrm{~mm}$ sodium phosphate, pH 7.0, 1 mM sodium pyrophosphate, and $50 \mathrm{~mm}$ dithiothreitol. After hybridization, coverslips
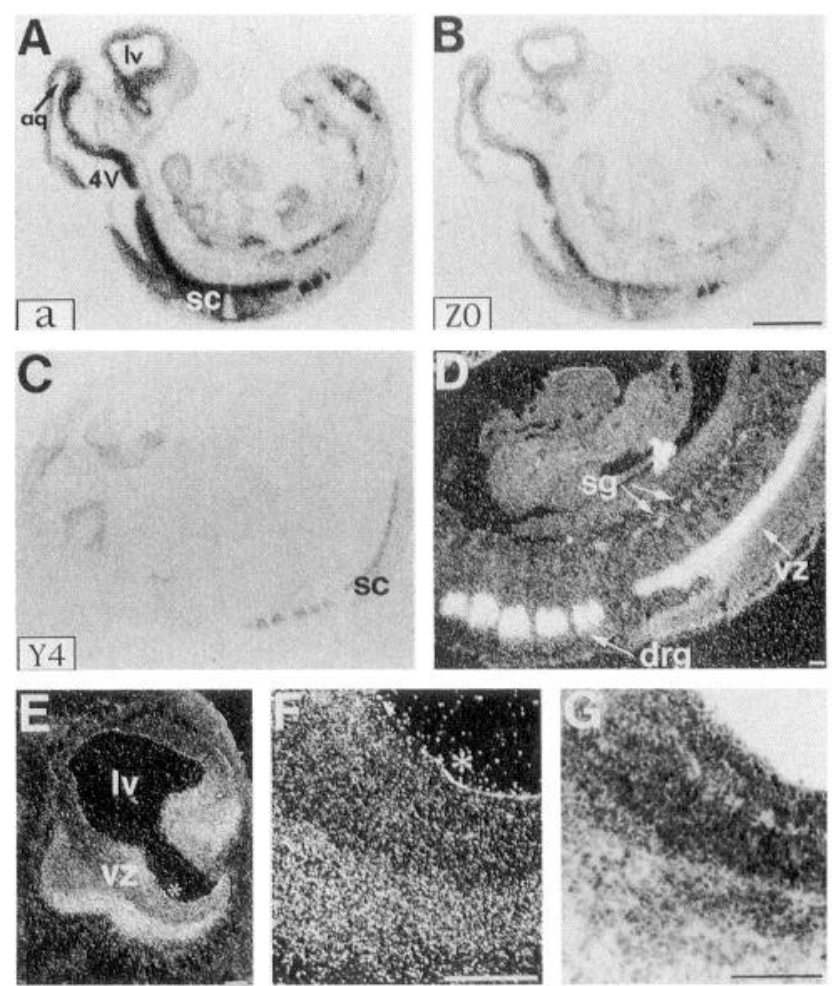

Figure 3. Agrin mRNA in E13 rat embryo. Film images of sagittal embryo sections $(A-C)$ show identical hybridization patterns for antisense $(A)$ and $\mathrm{ZO}(B)$ probes. In a slightly more lateral section, Y4 probe $(C)$ hybridized specifically to neural tissue but did not label other regions. Panels $D-F$ show higher magnification, dark-field images of an emulsion-dipped section adjacent to that shown in panel $C$, hybridized to the Y4 probe. Very dense labeling with the Y4 probe was seen in dorsal root ganglia and spinal cord ventricular zone; sympathetic ganglia were also prominently labeled $(D)$. In the brain $(E)$, Y4 hybridized to germinal cells immediately surrounding the lateral forebrain ventricle, and cells in the outlying neuroepithelial mantle. $F$ and $G$ show higher power dark-field and bright-field images, respectively, of region indicated by an asterisk in E. aq, aquaduct; $d r g$, dorsal root ganglia; $l v$, lateral ventricle; $s c$, spinal cord; $s g$, sympathetic ganglia; $v z$, ventricular zone; $4 v$, fourth ventricle. Scale bar: $1 \mathrm{~mm}(A-C)$ or $100 \mu \mathrm{m}(D-G)$.

were removed and slides were washed $10 \mathrm{~min}$ in $1 \times \mathrm{SSC}$ at room temperature, $40 \mathrm{~min}$ in $1 \times \mathrm{SSC}$ at $55^{\circ} \mathrm{C}$, dehydrated in ethanol $(70 \%$, $95 \%$ ), air dried, and apposed to $\beta$-max film (Amersham Corp.) for $5 \mathrm{~d}$. Slides were subsequently dipped in LM-1 emulsion (diluted 1:1 with $\mathrm{ddH}_{2} \mathrm{O}$; Amersham Corp.), and exposed at $4^{\circ} \mathrm{C}$ for $6-8$ weeks. Following autoradiographic development, sections were counterstained with hematoxylin, dehydrated through graded ethanols and coverslipped with Pro-Texx mounting medium (Baxter Scientific, McGaw Park, IL). Controls for hybridization specificity included either hybridization with a labeled "sense" oligonucleotide or, on some sections, inclusion of 100fold excess unlabeled oligonucleotide. Both methods yielded very low or absent "background" staining with no evidence of specific cellular labeling.

Southern blot. Full-length rat agrin cDNA isoforms Y4Z0, Y4Z8, Y4Z11, and Y4Z19 (obtained from R. H. Scheller, Stanford University) were digested with EcoRV and HindIII (New England Biolabs, Beverly, MA) resulting in the liberation of a 1.4 kilobase $(\mathrm{kb})$ fragment (base \#4446-5878) containing both the Y- and Z-splice sites, and aliquots of $200 \mu \mathrm{g}$ per lane were electrophoresed on a $1 \%$ agarose gel. Eight identical gels of the four isoforms were prepared, and the DNA was denatured and transferred to Gene Screen Plus hybridization membrane (Du Pont NEN, Boston, MA) by alkaline capillary transfer according to the manufacturer's protocol. DNA was fixed to the membrane by UV crosslinked-linking, and the eight blots hybridized separately to the eight rat agrin oligonucleotide probes. Probes were tailed with $\alpha-\left[{ }^{32} \mathrm{P}\right]-\mathrm{dATP}(>$ $3000 \mathrm{Ci} / \mathrm{mmol}$, Amersham Corp.) by terminal transferase to a specific 

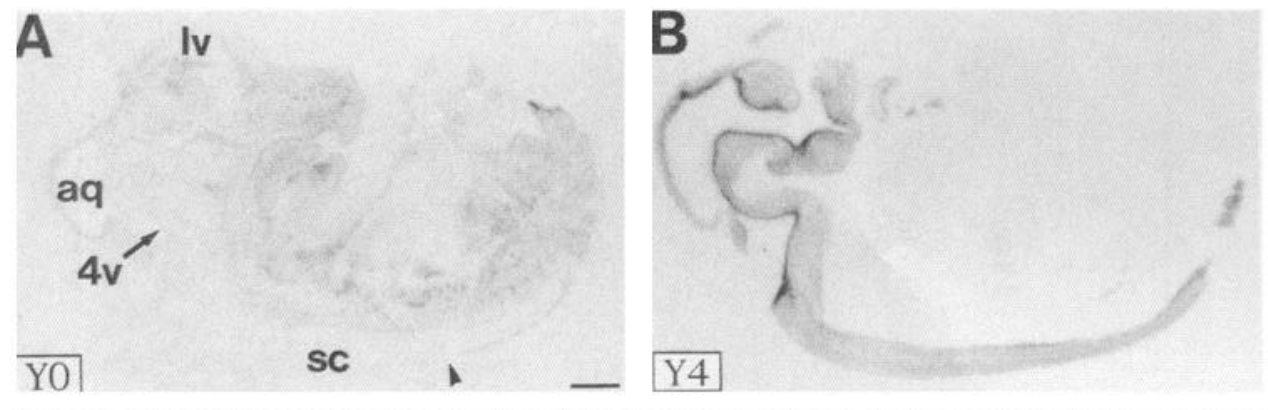

Figure 4. Hybridization of Y-isoform probes in rat E15 embryo. Film images of sagittal embryo sections hybridized with Y0 $(A)$ or Y4 $(B)$ probes revealed strikingly different expression patterns. Panels $C-E$ depict higher power, darkfield images of E15 spinal cord regions (arrowhead marks approximate location) from emulsion-dipped sections hybridized with Y0 $(C)$, Y4 $(D)$, or sense $(E)$ probes. $a q$, aquaduct; $d$, dor$\mathrm{sal} ; l v$, lateral ventricle; $m c$, motor column; $s c$, spinal cord; $v$, ventral; $v z$, ventricular zone; $4 \mathrm{~V}$, fourth ventricle. Scale bar: $1 \mathrm{~mm}(A$ and $B)$ or $300 \mu \mathrm{m}$ $(C-E)$.
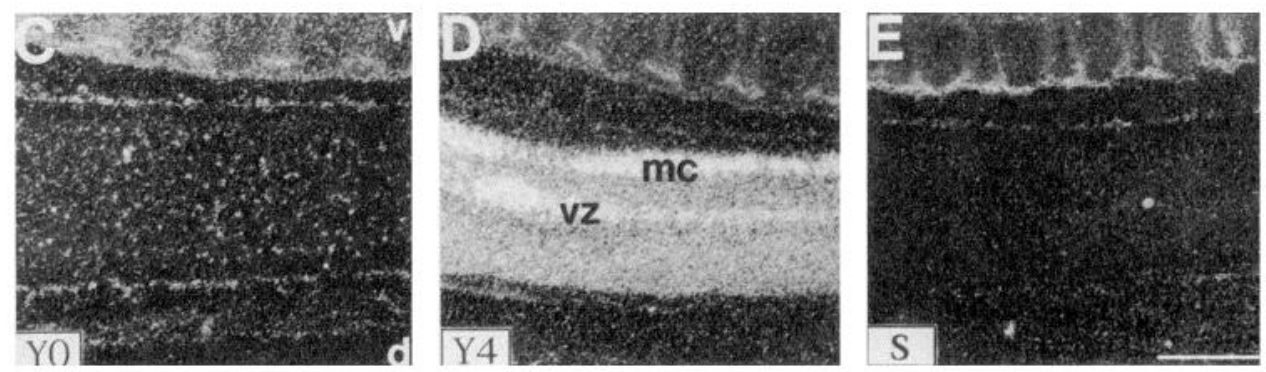

activity of $1 \times 10^{7} \mathrm{cpm} / \mu \mathrm{g}$, and used at $4 \times 10^{5} \mathrm{cpm} / \mathrm{ml}$ hybridization buffer. Hybridization buffer was: $50 \%$ formamide, $6 \times$ SSC, $5 \times$ Denhardt's, $50 \mathrm{~mm}$ sodium phosphate, $\mathrm{pH} 7.0,100 \mu \mathrm{g} / \mathrm{ml}$ polyadenylic acid, and $0.5 \%$ SDS; hybridization was carried out overnight at $52^{\circ} \mathrm{C}$ for Y-site probes and $42^{\circ} \mathrm{C}$ for all others. Blots were washed to a stringency of $1 \times \mathrm{SSC}$ at $55^{\circ} \mathrm{C}$ for $30 \mathrm{~min}$, and apposed to Kodak XAR-5 film for $8 \mathrm{hr}$.

Immunohistochemistry. Slide-mounted tissue sections (see above) were allowed to air dry for $30 \mathrm{~min}$ at room temperature, then placed in $4 \% \mathrm{PF}$ in phosphate buffer for $5 \mathrm{~min}$ at room temperature. Slides were subsequently washed $2 \times$ in PBS ( 5 min each), then placed in $1 \%$ NP40 in PBS for $5 \mathrm{~min}$ and in blocking buffer $(10 \%$ fetal calf serum in PBS) for $10 \mathrm{~min}$ at room temperature. A rabbit polyclonal antibody to CD34 (anti-mCD34; Baumhueter et al., 1993) was applied in blocking buffer at a dilution of 1:100 for $24 \mathrm{hr}$ at $4^{\circ} \mathrm{C}$. Slides were then washed $3 \times(4 \mathrm{~min}$ each) in PBS, and biotinylated goat anti-rabbit IgG (Vector Labs, Burlingame, CA) was applied as secondary antibody at a 1:100 dilution in blocking buffer. After a $1 \mathrm{hr}$ incubation, slides were washed in PBS ( $3 \times 4 \mathrm{~min})$ and incubated with FITC-labeled avidin D (Vector Labs), 1:100 in blocking buffer for $1 \mathrm{hr}$. Slides were washed in PBS and coverslipped with Vectashield mounting medium (Vector Labs).

\section{Results}

In situ hybridization, under stringency conditions favoring destabilization of short duplexes $(<20$ nucleotides; Wisden and Morris, 1994), was carried out on sections of rat tissue from developmental ages E13-adult. Six 36-mer oligonucleotides were synthesized as probes, designed to distinguish the six splice variants of agrin at the $\mathrm{Y}$ and $\mathrm{Z}$ sites. Additionally, two 36-mer oligonucleotides, designated antisense (recognizes all variants) and sense (reverse complement of antisense) were generated as positive and negative controls, respectively. Figure 1 diagrams the location of the splice sites in the encoded rat agrin protein, and the strategy used for designing the isoform-specific probes.

To demonstrate probe specificity, rat agrin cDNAs encoding the four different Z-site isoforms were subjected to Southern blotting. Under stringency conditions similar to those used for in situ hybridization, eight identical blots were hybridized individually with the eight labeled agrin oligonucleotide probes. As

Figure 5. Hybridization of Z-isoform probes in rat E15 embryo. Film images are shown of sagittal embryo sections hybridized with Z0 $(A)$ or Z19 (B) probes. Panels $C-F$ are dark-field images of E15 spinal cord regions (arrowhead in $A$ marks approximate location) from $\mathrm{Z} 0-(C), \mathrm{Z} 8(D)-, \mathrm{Z} 11$ $(E)$-, or Z19 $(F)$-labeled sections. Note specific hybridization of Z8 and Z19 only to ventral spinal cord (arrows in $D$ and $F$ ). Abbreviations and scale bars are as in Figure 3.
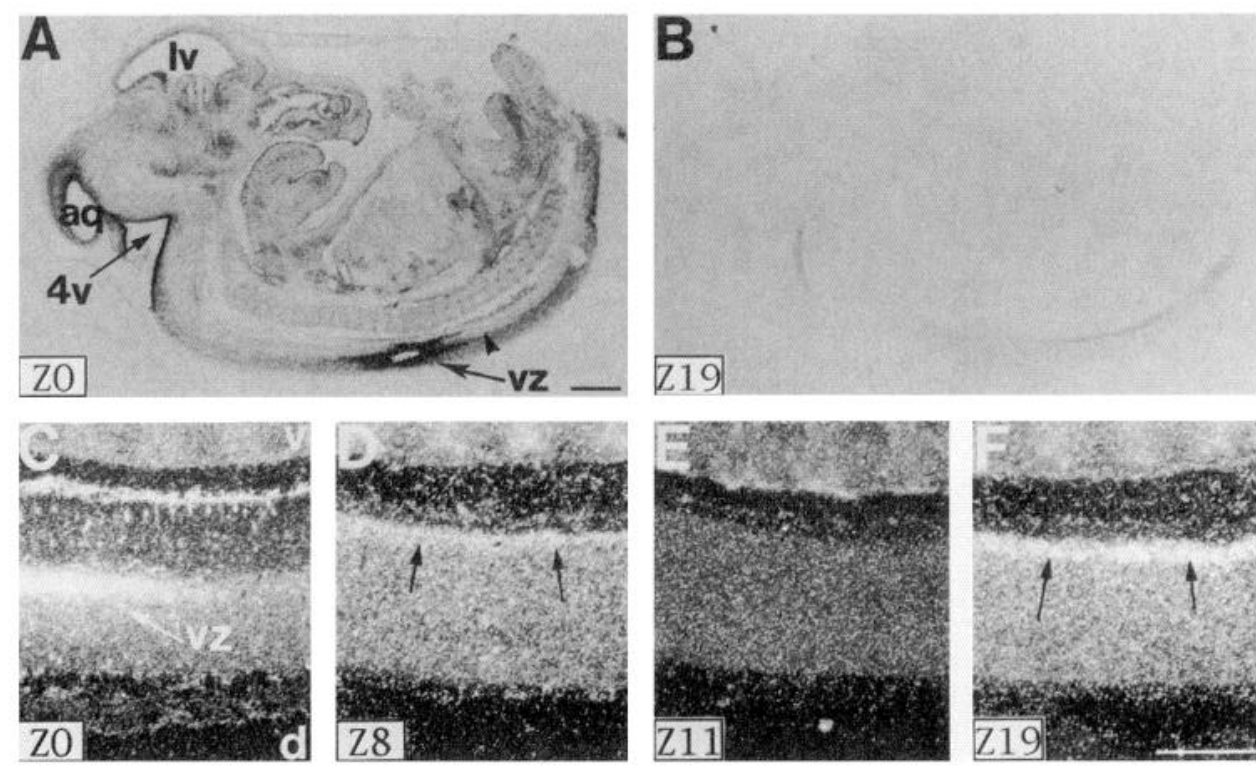
shown in Figure 2, each of the four Z-site probes hybridized specifically to its corresponding cDNA, with little or no crosshybridization to other Z-site variants (Fig. 2, upper panels). All four cDNAs tested contained the Y4 insert; thus, the Y4 probe hybridized to all, and the Y0 probe to none, of the cDNA variants (Fig. 2, lower panels). Additionally, all four cDNAs hybridized to both the antisense and the sense probes, due to the presence of both DNA strands. We did detect a faint crosshybridization of the $\mathrm{Z} 8$ probe to $\mathrm{Z} 19 \mathrm{cDNA}$; therefore, we cannot rule out the possibility that a minor fraction of the Z8-specific signal in vivo could be attributable to Z19 mRNA. However, we believe that the intensity of the $\mathrm{Z} 8$ signal in vivo, and its presence at later developmental stages when Z19 was not observed, suggest that the majority of this signal was specific to $\mathrm{Z} 8$ mRNA.

All eight labeled probes were hybridized individually to adjacent tissue sections at selected developmental ages. At E13, the earliest gestational age examined, agrin was strongly expressed in the developing nervous system (Fig. 3). Hybridization with the antisense probe revealed abundant message in mitotic ventricular zones of the spinal cord and brain; additionally, a widespread, above-background signal was detected in peripheral tissues (Fig. 3A). Hybridization with isoform-specific probes revealed that the Y4Z0 variant accounted for all the neurally expressed agrin observed at this age (Fig. $3 B, C$ ). Under dark-field optics, emulsion-dipped sections exhibited pronounced Y4 expression in developing spinal and sympathetic ganglia (Fig. 3D). In brain ventricular zones, Y4 message was predominantly localized to cells in the neuroepithelial mantle layer (Fig. $3 E-G$ ). The $\mathrm{Z} 0$ variant exhibited an expression pattern identical to that of Y4, with the addition of diffuse low-level expression in peripheral tissues; only the Y0 probe correspondingly localized to peripheral tissues (data not shown, but see Fig. $4 A$ for a later developmental age), suggesting a predominantly non-neuronal distribution of $\mathrm{Y} 0 \mathrm{Z} 0$ expression. No signal was detected for Z8 or Z11 probes, whereas the Z19 probe faintly hybridized to ventral lumbar spinal cord (data not shown).

At gestational age E15, strikingly different expression patterns were exhibited by the two Y-site splice variants (Fig. 4). Whereas the Y0 variant was expressed at a low-level throughout many peripheral tissues, and was only barely detectable in spinal cord and brain (Fig. 4A), Y4 was expressed abundantly and specifically within neural tissue: predominantly in mitotic ventricular zones and to a lesser extent throughout the entire spinal column and developing brain (Fig. $4 B$ ). Dark-field illumination of emulsion-dipped sections revealed the faint neural expression of the Y0 variant to be confined to capillaries and meninges (Fig. $4 C$, see also Fig. $6 C, E$ ); conversely, the Y4 variant diffusely labeled both gray and white matter of spinal cord (Fig. 4D), but was not expressed in vascular tissue. Figure $4 E$ depicts the low level of background labeling seen with the sense probe.

Of the Z-site variants, $\mathrm{Z} 0$ was the most abundantly expressed at this age (Fig. 5A), exhibiting a labeling pattern nearly identical to that of the $\mathrm{Y} 0$ and $\mathrm{Y} 4$ probes combined (compare Fig. $5 A$ to Fig. $4 A, B$ ). Thus, the major agrin isoforms expressed at E15 were Y4Z0 within the nervous system and Y0Z0 in non-neural tissues. Z19 specifically labeled ventral spinal cord (Fig. 5B), the region containing presumptive motor neurons. Z8 and Z11 hybridization could not be detected on x-ray film after a $5 \mathrm{~d}$ exposure (data not shown). At a higher magnification, dark-field images of lumbar spinal cord regions revealed that the $\mathrm{Z} 0$ variant was expressed in nearly all the regions in which the two Y-site
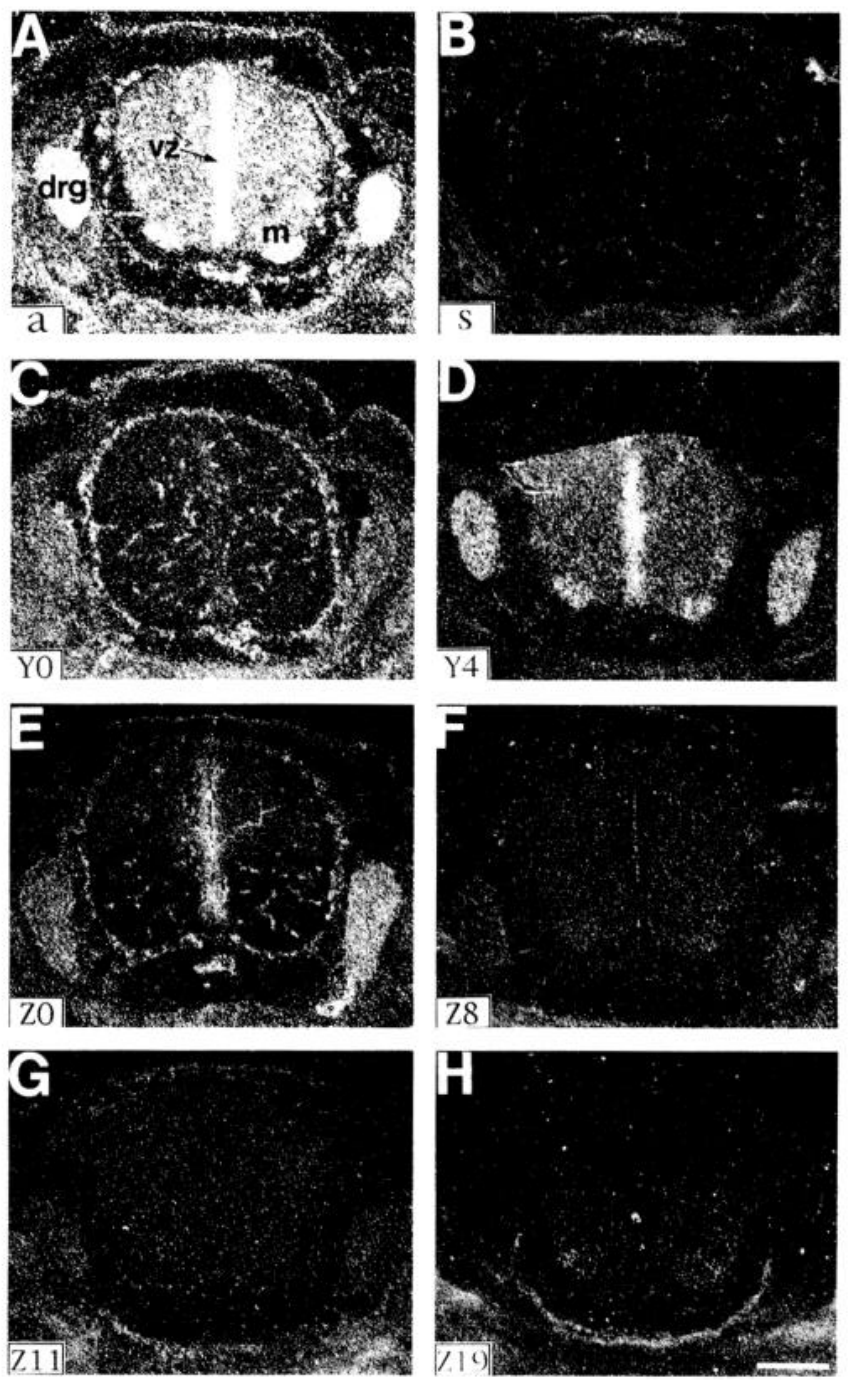

Figure 6. Agrin isoform mRNA in transverse sections of E15 lumbar spinal cord. Hybridization pattern seen with the antisense probe $(A)$ was a composite of the labeling patterns of Y0 $(C), \mathrm{Y} 4(D)$, and $\mathrm{Z} 0(E)$ probes combined. Note the diffuse, yet above-background signal, exhibited by the antisense, Y0, and $\mathrm{Z} 0$ probes in peripheral tissues. The sense probe $(B)$ showed a very low level of background labeling. Hybridization of $\mathrm{Z} 8, \mathrm{Z} 11$, and $\mathrm{Z} 19$ probes are shown in panels $F, G$, and $H$, respectively. Only $\mathrm{Z} 8$ and $\mathrm{Z} 19$ specifically hybridized to ventral spinal cord, the region containing presumptive motor neurons. $\mathrm{drg}$, dorsal root ganglia; $m$, motor column; $v$, ventricular zone. Scale bar: 300 $\mu \mathrm{m}$.

variants were detected: in germinal ventricular zones, spinal cord capillaries, and dura mater surrounding the spinal cord (Fig. 5C). Z8 and Z19 were expressed prominently in ventral motor columns, with a lesser diffuse labeling throughout spinal cord tissue (Fig. $5 D, F)$; message for the $\mathrm{Z} 11$ variant could not be detected (Fig. $5 E$ ).

Transverse sections of E15 lumbar spinal cord are shown in Figure 6 . Intense labeling with the antisense probe was detected in mitotic ventricular zones, dorsal root ganglia (DRG), ventral motor columns, and spinal cord meninges (Fig. 6A). Less abundant, but pronounced hybridization was detected throughout spinal cord tissue, within both gray and white matter, and a weaker diffuse hybridization signal was observed over several peripheral tissues (including muscle, skin, kidney and lung; data not shown, but see Fig. 13). Labeling patterns exhibited by individ- 

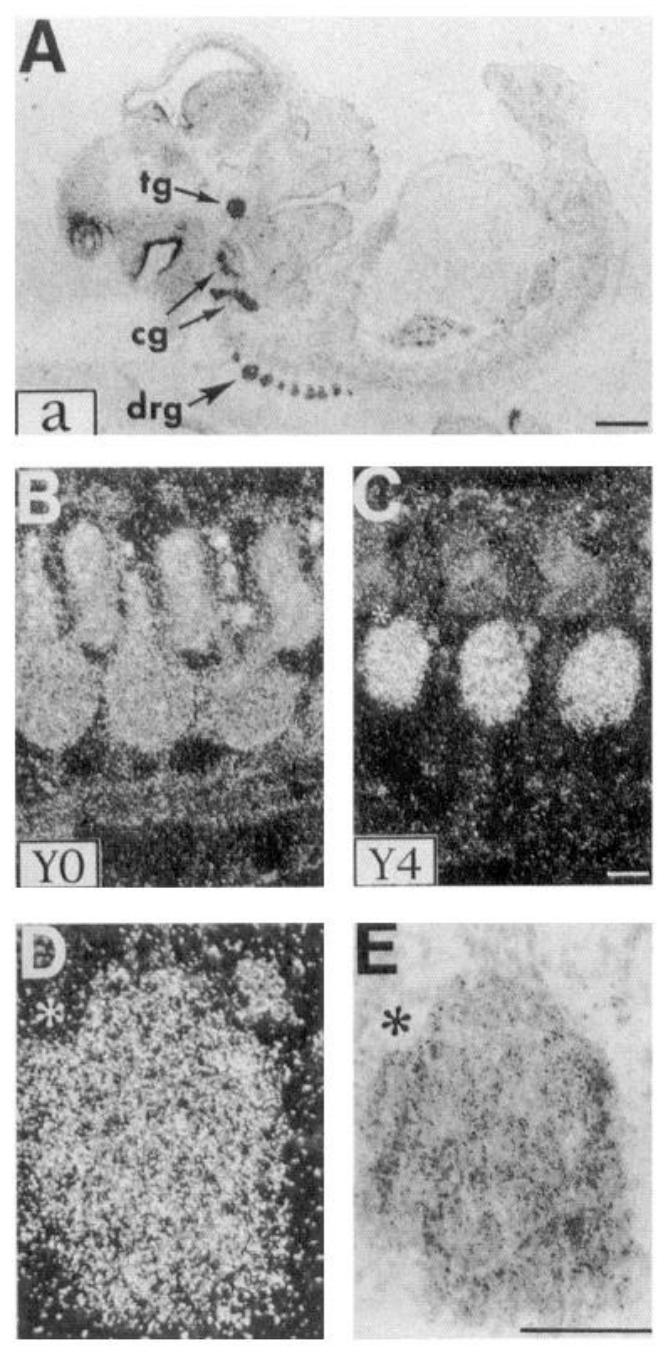

Figure 7. Agrin mRNA in developing spinal and cranial ganglia. A, Film image of antisense probe hybridized to an E15 sagittal embryo section, more lateral than those shown in Figures 3 and $4 . B$ and $C$ show higher power dark-field images of dorsal root ganglia from emulsion-dipped sections labeled with the Y0 $(B)$ or Y4 $(C)$ probes, respectively. The region indicated by an asterisk in $(C)$ is shown at higher power in dark-field $(D)$ and bright-field $(E) . c g$, cranial ganglia; $d r g$, dorsal root ganglia; $t g$, trigeminal ganglia. Scale bar: $1 \mathrm{~mm}(A)$ or 100 $\mu \mathrm{m}(B-E)$.

ual isoform-specific probes revealed the antisense pattern to be a composite of the component isoform variants. Thus, the major agrin isoform expressed in ventricular zone, DRGs, and diffusely throughout spinal cord tissue was Y4Z0 (Fig. 6D,E); that expressed in ventral motor columns was predominantly Y4Z19 and, to a lesser extent, Y4Z8 (Fig. $6 D, F, H$ ). Y0Z0 was expressed diffusely in peripheral tissues, and abundantly in both spinal cord capillaries and surrounding dura mater (Fig. 6C,E).

In addition to its prominent expression in the CNS, agrin was abundantly expressed in peripheral sensory ganglia. Figure $7 \mathrm{~A}$ depicts hybridization of the antisense probe to the trigeminal and other cranial ganglia; the isoform expressed in cranial ganglia was Y4Z0 (data not shown). Y4 (Fig. 7C) and Z0 (data not shown, but see Fig. $3 B$ ) variants were also colocalized in developing DRGs, whereas the Y0 probe (Fig. $7 B$ ) exhibited a much weaker, more diffuse hybridization signal, primarily concentrated over what appeared to be intervening blood vessels.
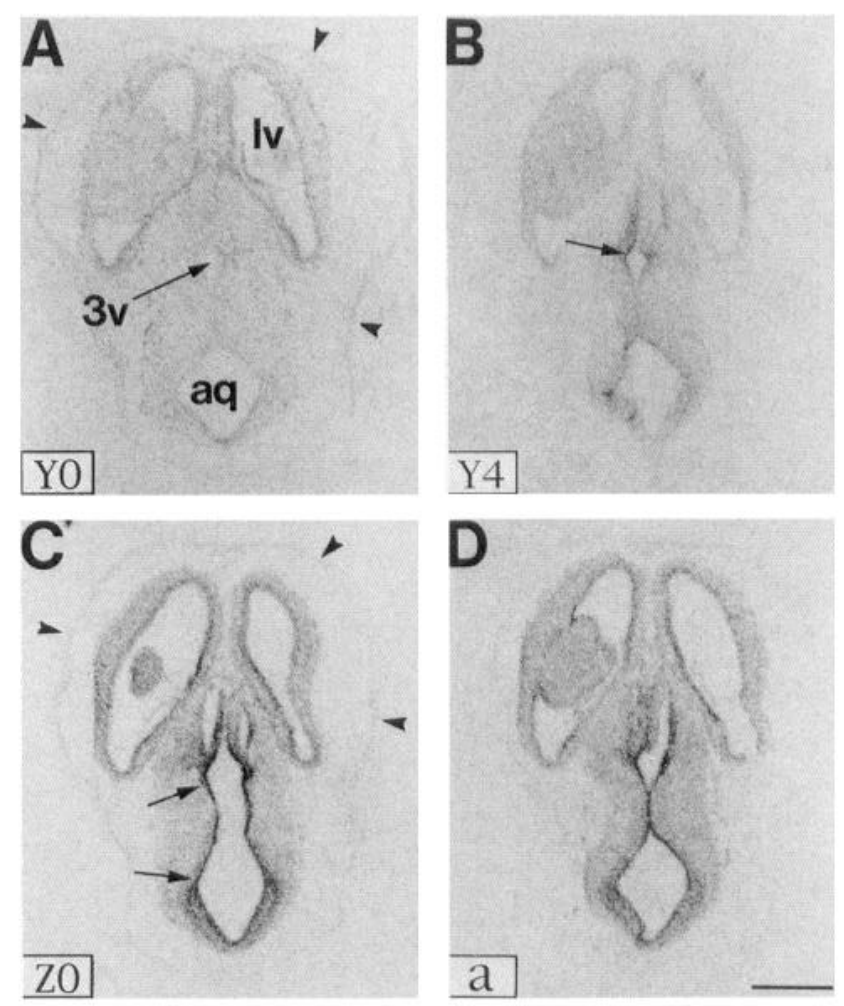

Figure 8. Agrin mRNA in developing brain. Film images of horizontal E15 brain show widespread expression of Y0 $(A), \mathrm{Y} 4(B)$, and $\mathrm{Z} 0(C)$ isoforms. Note ventricular labeling by Y4 and Z0 isoforms (arrows). Y0-and Z0-labeled brain meninges (arrowheads). D, Antisense probe hybridization. $a q$, aquaduct; $l v$, lateral ventricle; $3 v$, third ventricle. Scale bar: $1 \mathrm{~mm}$.

At higher power, the Y4 hybridization signal could not be localized to any specific cellular subset within DRGs, due to the close packing of cells within the ganglion at this developmental age (Fig. 7D,E).

Agrin message was abundantly expressed in developing (E15) brain (Fig. 8), the major transcripts being Y4Z0 and Y0Z0 (Fig. $8 A-C) . Z 8, Z 11$, and $\mathrm{Z} 19$ probes yielded a hybridization signal slightly above that of background, but the labeling appeared diffuse and was not localized to any specific brain region (data not shown). At a higher magnification and under dark-field optics, sagittal sections of E15 brainstem revealed several interesting features (Fig. 9B-F). Y4Z0 labeled mitotic zones surrounding the brain ventricles: most prominently, those surrounding the aquaduct, third, and fourth ventricles, and less prominently the forebrain ventricular zones (Fig. $9 C, D$ ). As in the spinal cord (see Fig. 6C,E), Y0Z0 message was expressed specifically within brain capillaries, and in the surrounding dura mater (Fig. $9 B, D)$. In an attempt to define the cellular localization of the YOZ0 isoform, adjacent brain sections were labeled with a polyclonal antibody to CD34 (Fig. $9 H-I$ ), a specific cell-surface marker for vascular endothelial cells (Fina et al., 1990). Under fluorescence optics, the immunohistochemical staining pattern of CD34 corresponded closely to the Y0 hybridization pattern, suggesting localization of the Y0Z0 message to capillary endothelial cells. Z8 and Z19 probe variants specifically labeled a brainstem motor nucleus, that of the facial nerve (Fig. 9E,F). Y4 (Fig. 9C) but not Y0 (Fig. 9B), message was also expressed in the facial motor nucleus, suggesting that both Y4Z8 and Y4Z19 isoforms are synthesized in brainstem motor neurons. 

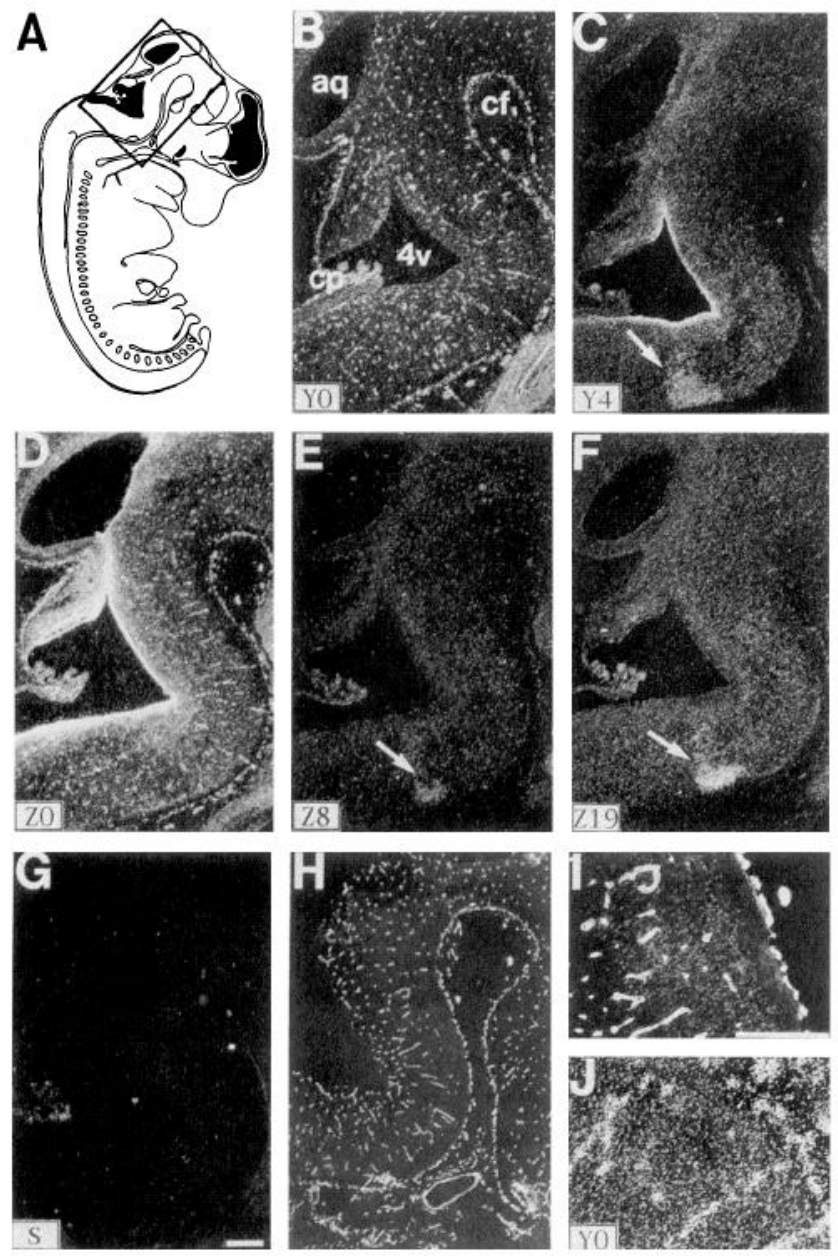

Figure 9. Higher power magnification of agrin isoform expression in E15 brainstem. Photomicrographs depict boxed region in $A$. Dark-field images of sagittal sections reveal hybridization of Y0 $(B), \mathrm{Y} 4(C), \mathrm{Z} 0$ $(D), \mathrm{Z} 8(E), \mathrm{Z} 19(F)$, and sense $(G)$ probes. Y4, Z8, and Z19 labeled specifically the motor nucleus of the seventh nerve (arrows in $C, E$, and $F$ ). $H$, Immunohistochemical localization of $\mathrm{CD} 34$, detected with an FITC-labeled secondary antibody and viewed under fluorescence optics. $I$ and $J$ show higher power views of CD34 staining and Y0 hybridization, respectively. $a q$, aquaduct; $c p$, choroid plexus; $c v$, cephalic flexure; $4 v$, fourth ventricle. Scale bars: $300 \mu \mathrm{m}$.

At a later stage in brain development (E19-P1) Y4Z0 was clearly the most abundant agrin variant, showing specific expression in developing cortex, corpus striatum, hippocampus, and cerebellum (Fig. 10A-C,E-G). Intense expression of Y4Z0 was also seen in diminishing mitotic ventricular zones surrounding the aquaduct and third ventricles (Fig. 10B,C). Whereas Y0Z0 expression could still be detected within brain capillaries at P1 (Fig. 10D), the signal appeared less intense than at earlier developmental ages.

In general, agrin expression appeared to decline throughout development, with the most intense hybridization signals appearing at the earliest ages examined. Figure 11 depicts a developmental profile of Z19 mRNA expression within spinal cord motor neurons. Hybridization signal intensity appeared strongest from ages E15-E18 (Fig. 11A-C), and thereafter declined slightly to P1 (Fig. 11D-E). Only very faint labeling was observed at P7 (Fig. 11F) and no Z19 hybridization could be detected in adult spinal cord (shown in Fig. $12 G$ ). Of the remaining $\mathrm{Z}$ isoforms, only $\mathrm{Z} 0$ and $\mathrm{Z} 8$ exhibited specific hybridization to adult spinal cord (Fig. 12D,E), the former as Y4Z0 within individual cells scattered throughout spinal cord gray matter (Fig. 12C,D), and the latter as Y4Z8 in motor neurons of the ventral spinal cord (Fig. 12C,E). Expression of the Y0Z0 isoform was not evident in capillaries in adult spinal cord sections (Fig. 12B).

In peripheral tissues, prominent expression of the $\mathrm{YOZO}$ isoform was observed in developing lung and kidney (Fig. 13A$D)$. Here, the label was associated with epithelial cells lining the developing lung bronchioles and kidney tubules (Fig. 13B,D). Interestingly, punctate agrin expression was seen in the liver, in which a small subset of scattered cells expressed Y0Z19 and, to a lesser extent, Y0Z8 isoforms (Fig. 13E,F).

Table 1 presents a summary of the developmental expression patterns of agrin isoforms from ages E13 to adult. With the exception of motor neurons, in which a developmentally regulated shift in isoform expression was observed, most other tissues maintained the expression of specific isoforms throughout development.

\section{Discussion}

In situ hybridization with isoform-specific oligonucleotide probes has allowed us to directly visualize and compare the developmental expression patterns of alternatively spliced agrin mRNAs. We show here unique and distinct tissue- and cell typespecific distributions of different $\mathrm{Y}$ - and Z-site agrin mRNA transcripts. Hybridization patterns of the six Y- and Z-site-specific oligonucleotide probes, when taken in sum, corresponded closely to the labeling pattern detected with a pan-specific antisense probe. Additionally, our antisense probe demonstrated a developmental hybridization profile that closely matched that of another pan-specific probe derived from a different region of the rat agrin cDNA (Biroc et al., 1993).

At E13, the earliest gestational age examined, agrin was very strongly expressed in mitotic ventricular zones and developing sensory and sympathetic ganglia (see Fig. 3); the predominant isoform was Y4Z0. Expression of Y4Z0 declined with developing age, correlating primarily with the birth and migration of neurons away from mitotic ventricular zones. By analogy to its proposed function in neuromuscular synapse formation, agrin has previously been hypothesized to play a role in synaptogenesis in the brain (Thomas et al., 1993; O'Connor et al., 1994). However, the pattern and time course of agrin expression seen here: i.e., in newly born neurons prior to their migration to outlying brain areas and long before they begin to send out axons to establish synaptic connections, suggest an additional role for agrin much earlier in neuronal development. One intriguing hypothesis derives from the presence of multiple follistatin-homologous regions in the $\mathrm{N}$-terminus of agrin, and the recently proposed role for follistatin as a neural inducer (Hemmati-Brivanlou et al., 1994). In Xenopus embryogenesis, follistatin is able to promote neuralization by binding directly to activin, a member of the transforming growth factor $\beta$ (TGF- $\beta$ ) superfamily, thus blocking the normal morphogenic activity of activin and allowing the default neural pathway to ensue. The multiple follistatin domains in agrin (Patthy and Nikolics, 1993) could serve a potentially analogous role in mammalian neurogenesis. Although agrin does not appear to bind activin (D. Stone and K. Nikolics, unpublished results), the follistatin-like repeats in agrin may bind to some other TGF- $\beta$ or related cysteine-knot superfamily member (McDonald and Hendrickson, 1993), which might be locally produced in or near agrin-expressing cells. At its location within extracellular matrix surrounding the cells in 

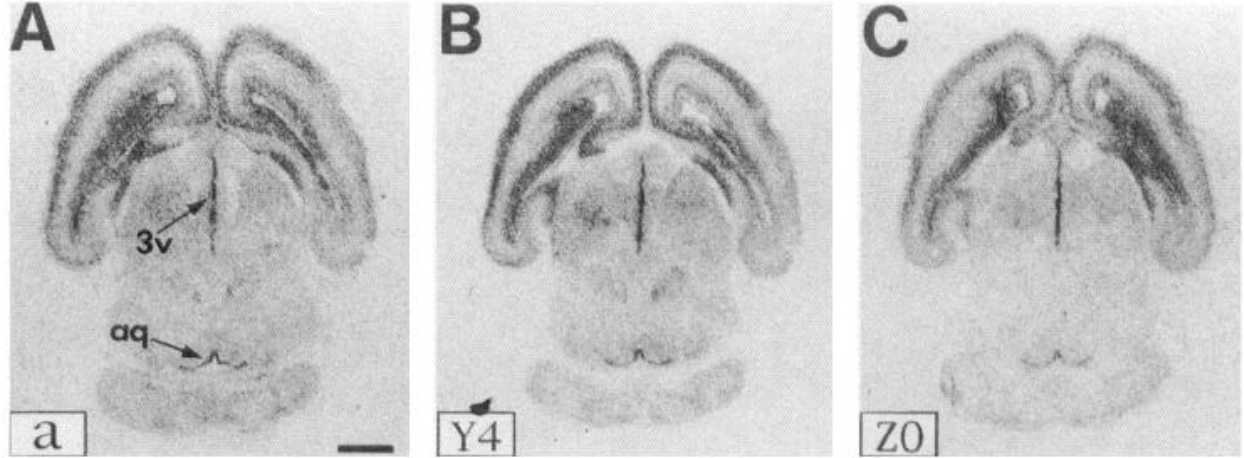

Figure 10. Agrin mRNA variants in E19-P1 brain. $A-C$ depict film images of horizontal E19 brain sections, hybridized to antisense $(A), \mathrm{Y} 4(B)$, or Z0 $(C)$ probes. Ventricular labeling is still evident at this age surrounding the aquaduct and third ventricle. Higher power dark-field images of emulsiondipped sections are shown in panels $D$ $H$. The region depicted is the rostral edge of the frontal cortex in horizontal sections from P1 brain. Hybridization patterns of $\mathrm{Y} 0(D), \mathrm{Y} 4(E), \mathrm{Z} 0(F)$, antisense $(G)$, and sense $(H)$ probes are shown. $a q$, aquaduct; $3 v$, third ventricle; $c c$, corpus callosum; str, neostriatum; $l v$, lateral ventricle. Scale bars: 1 $\mathrm{mm}$.
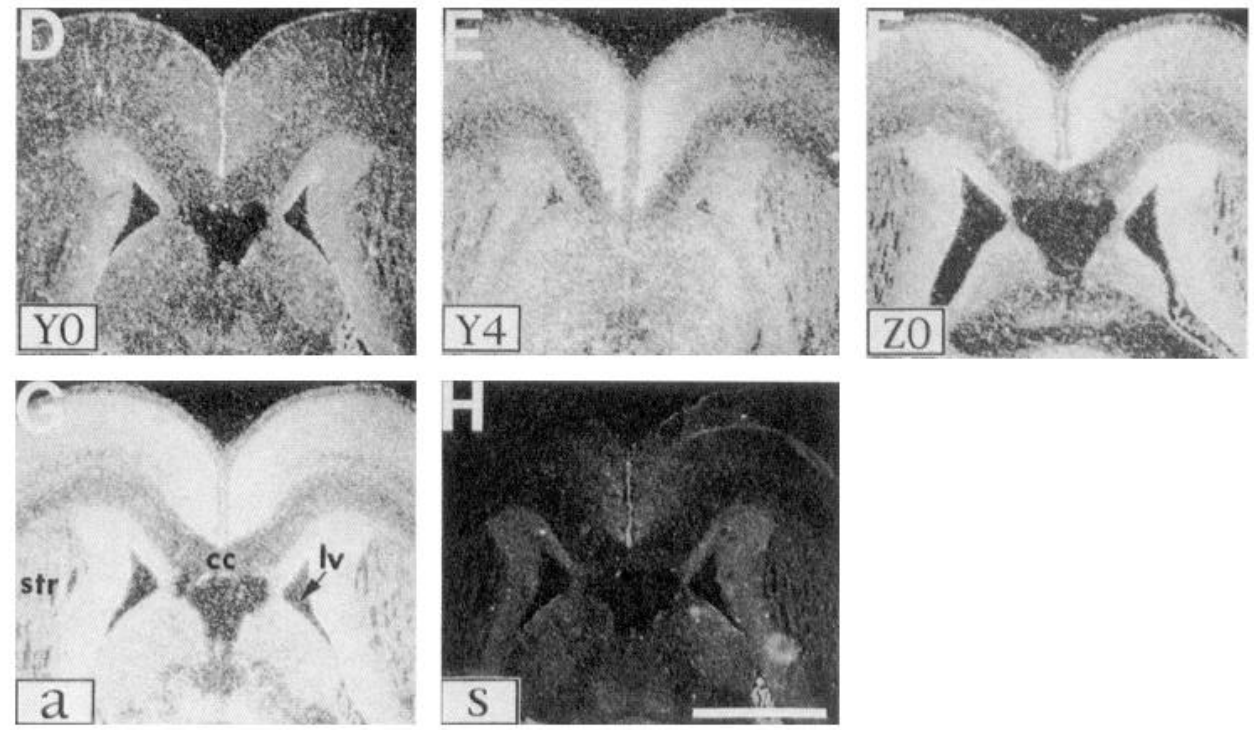

which it is produced, agrin could act to bind, and thus regulate the function and availability of a growth factor involved in the mitogenesis or differentiation of agrin-expressing cells (Patthy and Nikolics, 1993, 1994).

Distribution patterns of the mRNA transcripts for Y-site variants differed strikingly (see Fig. 4). The alternative splicing event leading to insertion of a 12-nucleotide sequence encoding the amino acids KSRK, corresponding to exon 28 of the mouse gene (Y4; Rupp et al., 1992), occurred only within nervous tissue, including spinal cord, brain, and cranial, spinal and sympathetic ganglia. In contrast, the mRNA transcript encoding no insert at this site (Y0) was detected only in non-neural tissues, including skin, muscle, kidney, lung, and vascular tissues. Our results are in agreement with a prior study using PCR analysis to examine expression patterns of agrin variants (Hoch et al., 1993). These investigators reported a tissue-specific distribution of alternatively spliced Y- and Z-site isoforms: whereas the Y4 variant was expressed primarily in neural tissues, the Y0 variant was expressed in all tissues examined. However, unlike the previous study, which reported a minor (5-20\%) expression of the Y4 variant in heart, muscle, and other non-neural tissues, we did not detect any non-neural expression of the Y4 variant by in situ hybridization.

Of the Z-site variants, $\mathrm{Z} 0$ was the most widely expressed transcript, encoding the majority of both neurally (in the form of $\mathrm{Y} 4 \mathrm{Z0}$ ) and non-neurally expressed (Y0Z0) agrin protein isoforms. Tissue hybridization patterns of the $\mathrm{Z} 0$ probe appeared nearly identical to those of the antisense probe, yet were often of a slightly lower signal intensity (see, for example, Fig. $3 A, B$ ). Transcripts encoding the Z8 and Z19-containing isoforms were expressed diffusely at a very low level in brain tissue and spinal cord; specific localized expression was detected only within motor neuron cell bodies, in both ventral spinal cord and brainstem. Additionally, expression of the Z19 transcript was most pronounced at early developmental ages (E15-E18), the period corresponding to peripheral synapse formation. The $\mathrm{Z} 8$ variant was detected in all regions that expressed Z19, yet at a slightly lower concentration; a notable exception was observed in adult spinal cord, in which only $\mathrm{Z} 8$, but not $\mathrm{Z19}$, was detected in motor neuron cell bodies. Our data agree with those of Hoch and coworkers (1993), suggesting that a developmentally regulated shift in agrin splicing patterns occurs within motor neurons. The exclusive expression of the Z8 and Z19 isoforms in motor neurons is compatable with a role for these insert-containing isoforms as the neuron-derived inducers of muscle fiber AChR aggregation, since only those agrin variants most active in receptor clustering assays in vitro (Fern et al., 1993; Daggett et al., 1994) were expressed in the appropriate cells at the time of initial synapse formation. Additionally, in agreement with Ruegg et al. (1992), we found splicing of inserts at the Y- and Z-sites to be coordinately regulated, since only the Y4, but not the Y0 transcript, was colocalized with Z-insert containing forms in presumptive motor neurons. An unusual variation, however, was observed in liver, in which scattered cells appeared to express either Y0Z8 or Y0Z19 isoforms. We currently have no explanation for this finding. We did not observe any specific hybrid- 

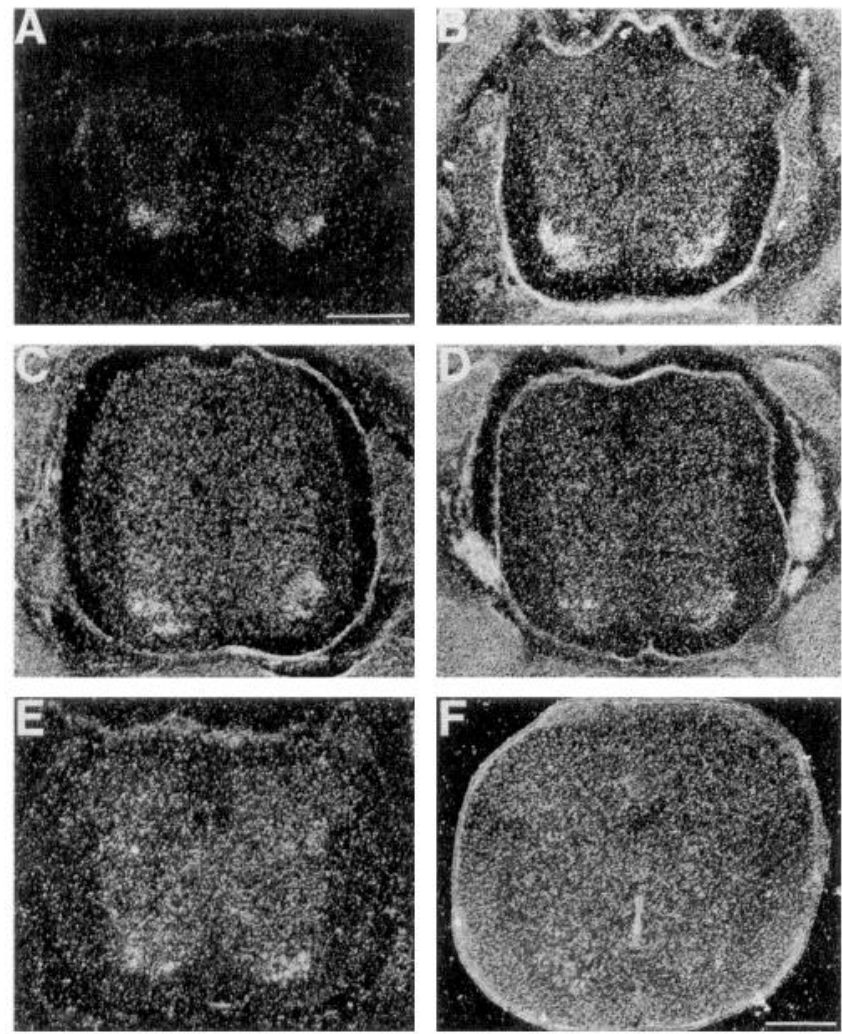

Figure 11. Developmental decline of agrin Z19 expression in spinal cord motor neurons. Dark-field images of transverse sections through lower thoracic spinal cord hybridized to Z19 probe are shown at ages E15 $(A)$, E16 $(B)$, E18 $(C)$, E19 $(D), \mathrm{Pl}(E)$, and P7 $(F)$. Peak expression occurred from E16-E18. Scale bar: $300 \mu \mathrm{m}$.

ization with the Z11 probe variant, suggesting that expression of this isoform was either absent or below the level of detectability under our assay conditions. In this regard, our data conflict with those of Hoch and co-workers (1993), who found by PCR significant levels of Z11 mRNA in brain and spinal cord at comparable developmental stages.

The $\mathrm{Y}$ and $\mathrm{Z}$ sites of the agrin protein are located, respectively, within the second and third of three laminin A modules in the C-terminal portion of the protein; these modules are hypothesized to specify independent globular folding units, similar to the G-domain of laminin A (Beck et al., 1991; Patthy and Nikolics, 1994). In the case of laminin, this domain binds to proteoglycans within extracellular matrix (Ott et al., 1982) and to a dystroglycan-related protein from embryonic brain (Gee et al., 1993). In agrin, these modules are important for binding to $\alpha$-dystroglycan (Hoch et al., 1994), a potential agrin receptor (Bowe et al., 1994; Campanelli et al., 1994; Gee et al., 1994; Sugiyama et al., 1994). It seems reasonable to predict that the insert status at the $\mathrm{Y}$ and $\mathrm{Z}$ sites may influence protein activity by altering the structural folding of this region of the molecule and, hence, interaction of agrin with its receptor. Inserts at the $\mathrm{Z}$ site have been shown to induce an apparent conformational change in protein structure, detected by the appearance of a new monoclonal antibody epitope (Hoch et al., 1994). However, no differences in binding affinity of the different agrin isoforms for $\alpha$-dystroglycan have yet been detected (Sugiyama et al., 1994).

The regulatory factors involved in agrin splice site selection remain currently unexplored. Several examples of neuron-spe-
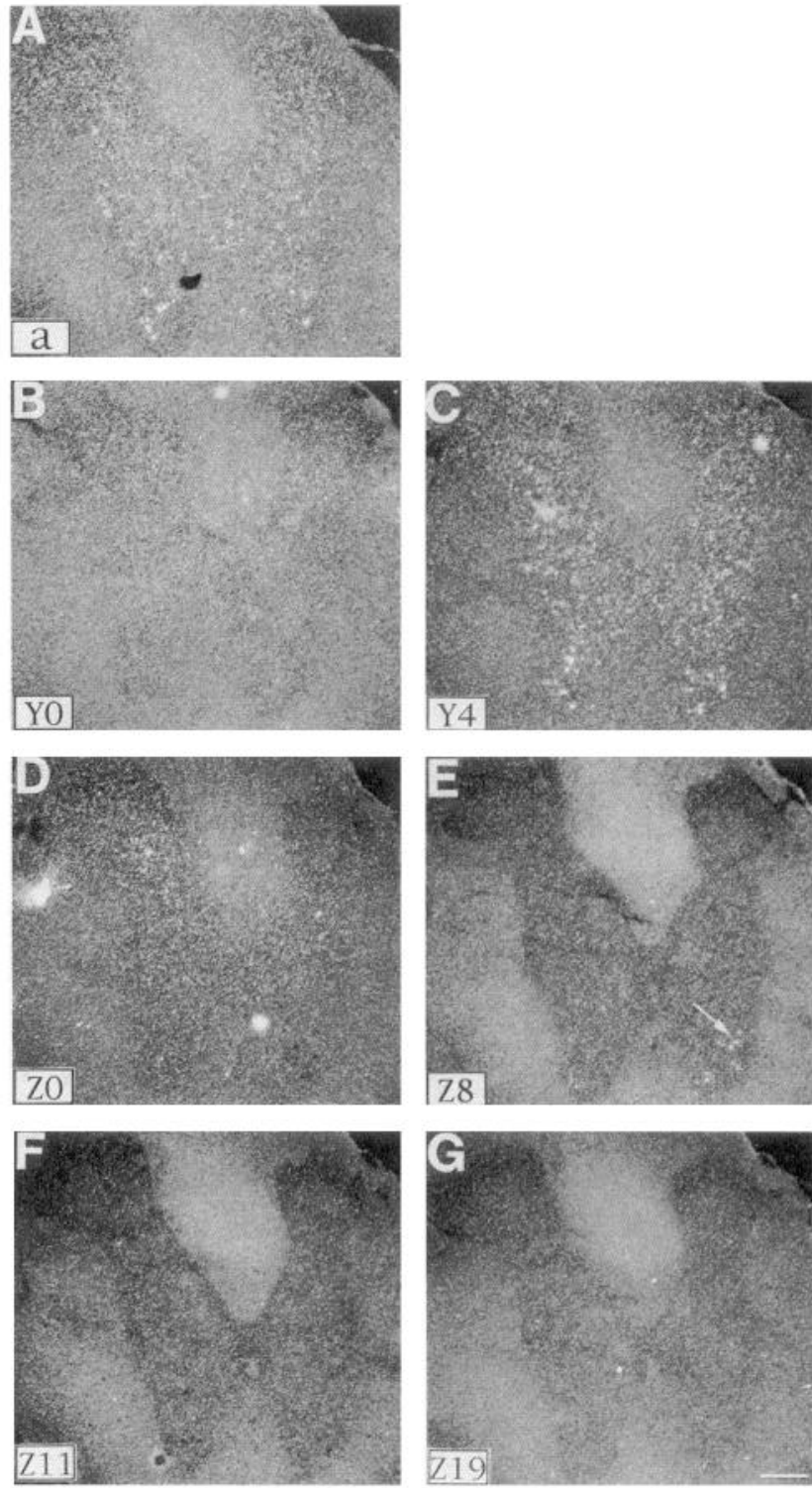

Figure 12. Agrin isoform mRNA in adult spinal cord. Dark-field images of transverse sections through thoracic spinal cord hybridized with antisense $(A), \mathrm{Y} 0(B), \mathrm{Y} 4(C), \mathrm{Z} 0(D), \mathrm{Z} 8(E), \mathrm{Z} 11(F)$, or Z19 $(G)$ probes. Only the antisense, $Y 4$, and $Z 8$ probes specifically labeled ventral horn motor neurons (arrows). Scattered neurons elsewhere within gray matter were labeled with the $\mathrm{Y} 4$ and $\mathrm{Z} 0$ probes, and the $\mathrm{Y} 0$ probe exhibited a diffuse, above-background signal over both gray and white matter. Scale bar: $300 \mu \mathrm{m}$.

cific exon splicing have been described previously (Stamm et al., 1992; Had et al., 1993; Schell et al., 1993; Yamada et al., 1993). One well-studied example is that of the c-src oncogene, in which insertion of an 18-nucleotide exon, alone or in conjunction with a 33-nucleotide exon, occurs specifically in neurons; these isoforms are excluded from other tissues in which c-src is expressed (Levy et al., 1987; Martinez et al., 1987). In this and other studies, the cis-acting sequence elements responsible for the neuron-specific splicing event were localized to the optional exons and their flanking intronic sequences (Black, 1992; Stamm et al., 1993; Yamada et al., 1993). An emerging view from these studies is that cell type- and age-specific differences in the relative concentrations or activities of trans-act- 

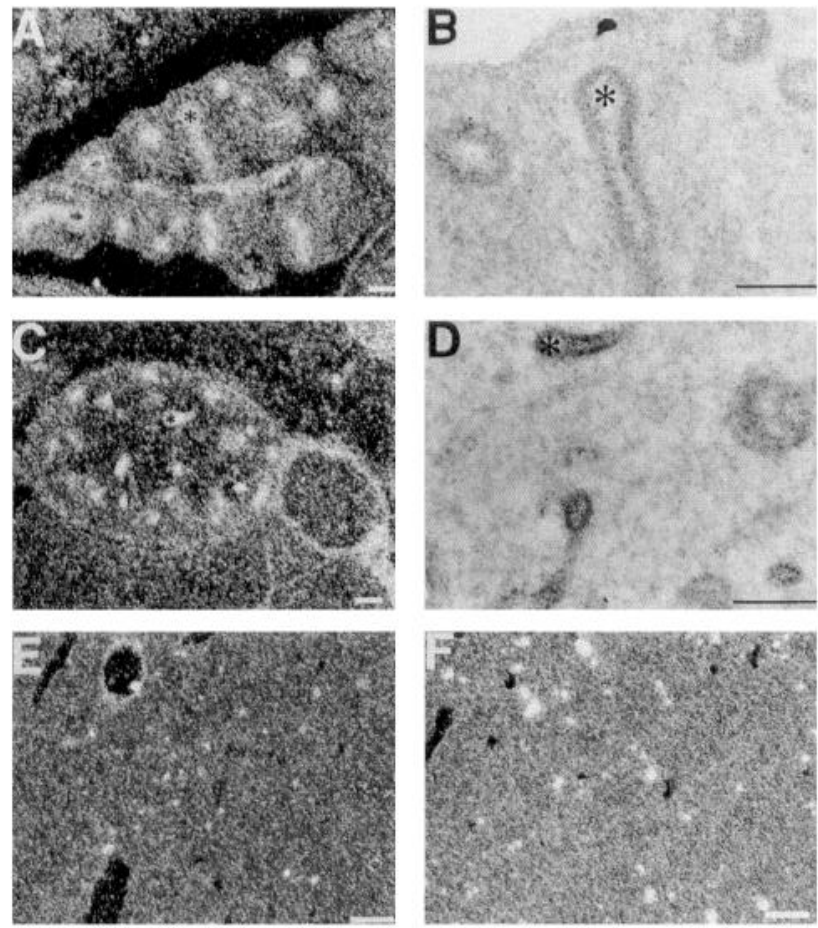

Figure 13. Specific expression of agrin mRNA in non-neuronal tissues. Under dark-field optics, dense hybridization of the Y0 probe was observed in E15 lung $(A)$ and kidney $(C)$. Higher power, bright-field images of regions indicated by asterisks in $A$ and $C$, respectively, show label to be concentrated over epithelial cells lining the developing lung bronchioles $(B)$, and kidney tubules $(D)$. Panels $E-F$ depict the punctate hybridization pattern seen in embryonic liver with Y0 $(E)$ and Z19 $(F)$ probes. Scale bars: $100 \mu \mathrm{m}$.

ing factors, i.e., both small nuclear ribonucleoproteins (snRNPs) and non-snRNP RNA-binding proteins that function as essential elements of the constitutive splicing aparatus, may serve to regulate splice site selection (see Rio, 1993; Norton, 1994, for review).

A novel finding from the present study was the specific expression of the Y0Z0 agrin variant in brain and spinal cord capillary endothelial cells. Immunohistochemical staining with anti-agrin antibodies have previously localized agrin protein to capillaries throughout the CNS of chick (Magill-Solc and McMahan, 1988; Godfrey, 1991), rat (Rupp et al., 1991), frog, and Torpedo (Magill-Solc and McMahan, 1988), as well as the surface of the brain and spinal cord (Magill-Solc and McMahan, 1988). Electron microscopy revealed that the label associated with capillaries was concentrated in the basal lamina lying be- tween the capillaries and the astrocyte end-foot processes (Magill-Solc and McMahan, 1988). Our data suggest endothelial cells to be the source of the capillary-associated agrin, since immunohistochemical staining with a specific marker for endothelial cells showed an identical distribution pattern; presumably, agrin is synthesized in the endothelial cell and secreted from the baso-lateral side, becoming subsequently incorporated into the underlying extracellular matrix. The presence of agrin message in vascular endothelial cells at early developmental ages suggest a potential novel role for agrin in angiogenesis. One intriguing possibility is a role for agrin in blood-brain barrier formation or maintenance, since agrin appeared to be expressed specifically in brain and spinal cord capillary endothelium, but not in non-neural vasculature (however, Y0Z0 expression in peripheral capillaries could have been masked by the low level, diffuse hybridization signal exhibited throughout the periphery). The recent identification of $\alpha$-dystroglycan as an agrin-binding protein (Bowe et al., 1994; Campanelli et al., 1994; Gee et al., 1994; Sugiyama et al., 1994), and the previously characterized association between $\alpha$-dystoglycan, the dystrophin-glycoprotein complex (an oligomeric complex that spans the plasma membrane; Ervasti and Campbell, 1991), and actin (Ervasti and Campbell, 1993) suggest that a primary function of agrin may be to act as an extracellular matrix-cytoskeletal link. Such a link could serve to organize local cell surface specializations during development, including not only the clustering of neurotransmitter receptors in postsynaptic membranes, but the establishment of domains involved in cell polarization or intercellular contact, such as the capillary endothelial cell tight junctions that underly the structural basis of the blood-brain barrier (Bradbury, 1993). One specific type of membrane specialization, the orthogonal intramembraneous particle assemblies that are found highly concentrated in perivascular astroglial end feet, can be induced by coculture of astocytes with either brain endothelial or meningeal cells (Tao-Cheng et al., 1990). Additionally, these assembly patches correlate with the presence of basal lamina, suggesting that the inducing factor(s) is concentrated in the basal lamina lying between brain endothelial and astroglial cells.

The Y0Z0 agrin isoform was also expressed prominently in epithelial cells lining the developing lung bronchioles and kidney tubules; the latter could represent the source of agrin immunoreactivity identified in kidney extracellular matrix (Godfrey, 1991). The early (E15) expression of agrin in these epithelial cell populations is consistent with a role for this isoform in the organization or establishment of cell polarization, particularly in light of the three laminin $\mathrm{G}$ domain homologous regions in the C-terminal third of agrin, a domain hypothesized to mediate the epithelial cell polarity induced both by laminin

Table 1. Agrin isoforms expressed in various tissues during development

\begin{tabular}{llll} 
& E15-E19 & P1 & Adult \\
\hline $\begin{array}{l}\text { CNS ventricular zones, spinal and } \\
\text { cranial ganglia }\end{array}$ & Y4Z0 & Y4Z0 & n.d. \\
Brain & $\mathrm{Y}^{a} 0^{a}$ & Y4Z0 & Y4Z0 \\
Motor neurons & Y4Z19 $>$ Z8 & Y4Z8 $>$ Z19 & Y4Z8 \\
CNS capillary endothelial cells & Y0Z0 & Y0Z0 & - \\
Muscle, lung, kidney & Y0Z0 & Y0Z0 & n.d. \\
\hline
\end{tabular}

n.d., not determined; - , undetectable.

${ }^{a}$ Detected as early as E13. 
and the Drosophila protein crumbs (Klein et al., 1988; Patthy, 1991).

In conclusion, mRNA transcripts for differentially spliced agrin variants were shown to have unique and distinct cell typespecific distribution patterns, suggesting that agrin protein expression is subject to complex regulation during mammalian development. While optional exon usage predicts the possibility of eight different agrin isoforms at the $\mathrm{Y}$ and $\mathrm{Z}$ sites, we detected only four predominant mRNA transcripts in vivo: Y4Z0, YOZO, Y4Z8, and Y4Z19. In agreement with PCR and Northern analyses, forms containing inserts at both the $Y$ and $Z$ sites werc expressed specifically within neural tissue, whereas the insertless isoform was localized only to peripheral tissues. The expression of the two Z-insert-containing isoforms in spinal motor neurons correlated with the proposed role of neural agrin in regulating AChR aggregation. However, the remaining two isoforms, which comprised the majority of the agrin expressed, exhibited distribution profiles suggestive of biological functions for agrin beyond its originally proposed activity, including potential roles in neurogenesis (Y4Z0) and nervous system endothelial cell differentiation (YOZ0). With the availability of specific agrin isoforms produced by recombinant methods in vitro, we can begin to explore some of the potential novel developmental roles for agrin isoforms presented here.

\section{References}

Baumhueter S, Singer MS, Henzel W, Hemmerich S, Renz M, Rosen SD, Lasky LA (1993) Binding of L-selectin to the vascular sialomucin CD34. Science 262:436-438.

Beck K, Spring J, Chiqet-Ehrismann R, Engel J, Chiqet M (1991) Structural motifs of the extracellular matrix proteins laminin and tenascin. Springer Ser Biophys 7:231-256.

Biroc S L, Payan DG, Fisher JM (1993) Isuforms of agrin are widely expressed in the developing rat and may function as protease inhibitors. Dev Brain Res 75:119-129.

Black DL (1992) Activation of c-src neuron-specific splicing by an unusual RNA element in vivo and in vitro. Cell 69:795-807.

Bowe MA, Deyst KA, Leszyk JD, Fallon JR (1994) Identification and purification of an agrin receptor from Torpedo postsynaptic membranes: a heteromeric complex related to the dystroglycans. Neuron $12: 1173-1180$.

Boyd CD, Pierce RA, Schwarzbauer JE, Doege K, Sandell LJ (1993) Alternative exon usage is a commonly used mechanism for increasing coding diversity within genes coding for extracellular matrix proteins. Matrix 13:457-469.

Bradbury MW (1993) The blood-brain barrier. Exp Physiol 78:453472.

Breitbart RE, Andreadis A, Nadal-Ginard B (1987) Alternative splicing: a ubiquitous mechanism for the generation of multiple protein isoforms from single genes. Annu Rev Biochem 56:467-495.

Campanelli JT, Hoch W, Rupp F, Kreiner T, Scheller R (1991) agrin mediates cell contact-induced acetylcholine receptor clustering. Cell 67:909-916.

Campanelli JT, Roberds SL, Campbell KP, Scheller RH (1994) A role for dystrophin-associated glycoproteins and utrophin in agrin-induced AChR clustering. Cell 77:663-674.

Daggett DF, Stone D, Hassell JR, Nikolics K, Peng HB (1994) The effect of agrin isoforms on cultured Xenopus myotomal muscle cells. Mol Biol Cell Suppl 5:236a.

Ervasti JM, Campbell KP (1991) Membrane organization of the dystrophin-glycoprotein complex. Cell 66:1121-1131.

Ervasti JM, Campbell KP (1993) A role for the dystrophin-glycoprotein complex as a transmembrane linker between laminin and actin. J Cell Biol 122:809-823.

Ferns M, Hoch W, Campanelli JT, Rupp F, Hall ZW, Scheller RH (1992) RNA splicing regulated agrin-mediated acetylcholine receptor clustering activity on cultured myotubes. Neuron 8:1079-1086.

Ferns MJ, Campanelli JT, Hoch W, Scheller RH, Hall Z (1993) The ability of agrin to cluster AChRs depends on alternative splicing and on cell surface proteoglycans. Neuron 11:491-502.
Fina L, Molgaard DR, Robertson D, Bradley NJ, Monaghan P, Delia D, Sutherland DR, Baker MA, Greaves MF (1990) Expression of the CD34 gene in vascular endothelial cells. Blood 75:2417-2426.

Gee SH, Blacher RW, Douville PJ, Provost PR, Yurchenco PD, Carbonetto $S$ (1993) Laminin-binding protein 120 from brain is closely related to the dystrophin-associated glycoprotein, dystroglycan, and binds with high affinity to the major heparin binding domain of laminin. J Cell Biol Chem 268:14972-10.

Gee SH, Montanaro F, Lindenbaum MH, Carbonetto S (1994) Dystroglycan- $\alpha$, a dystrophin-associated glycoprotein, is a functional agrin receptor. Cell 77:675-686.

Had L, Faivre-Sarrailh Legrand C, Rabie A (1993) The expression of tropomyosin genes in pure cultures of rat neurons, astrocytes and oligodendrocytes is highly cell-type specific and strongly regulated during development. Mol Brain Res 18:77-86.

Hall ZW, Sanes JR (1993) Synaptic structure and development: the neuromuscular junction. Cell 72/Neuron Suppl 10:99-121.

Hemmati-Brivanlou A, Kelly OG, Melton DA (1994) Follistatin, an antagonist of activin, is expressed in the Spemann organizer and displays direct neuralizing activity. Cell 77:283-295.

Hoch W. Ferns M, Campanelli JT, Hall ZW, Scheller RH (1993) Developmental regulation of highly active alternatively spliced forms of agrin. Neuron 11:479-490.

Hoch W, Campanelli JT, Harrison S, Schcller RH (1994) Structural domains of agrin required for clustering of nicotinic acetylcholine receptors. EMBO J 13:2814-2821.

Honig LS, Stone D, Nikolic K, McMahan UJ (1993) agrin isoforms in developing chick motor neurons. Soc Neurosci Abstr 19:1272.

Klein G, Langegger M, Timpl R, Ekblom P (1988) Role of laminin A chain in the development of epithelial cell polarity. Cell 55:331-341.

Ma E, Morgan R, Godfrey EW (1994) Distribution of agrin mRNAs in the chick embryo nervous system. J Neurosci 14:2943-2952.

Magill-Solc C, McMahan UJ (1988) Motor neurons contain agrin-like molecules. J Cell Biol 107:1825-1833.

Magill-Solc C, McMahan UJ (1990) Synthesis and transport of agrinlike molecules in motor neurons. J Exp Biol 153:1-10.

McDonald NQ, Hendrickson WA (1993) A structural superfamily of growth factors containing a cystine knot motif. Cell 73:421-424.

McMahan UJ (1990) The agrin hypothesis. Cold Spring Harbor Symp Quant Biol 55:407-418.

Nitkin RM, Rothschild TC (1990) agrin-induced reorganization of extracellular matrix components on cultured myotubes: relationship to AchR aggregation. J Cell Biol 111:1161-1170.

Nitkin RM, Smith MA, Magill C, Fallon JR, Yao Y-MM, Wallace BG, McMahan UJ (1987) Identification of agrin, a synaptic organizing protein from Torpedo electric organ. J Cell Biol 105:2471-2478.

Norton PA (1994) Alternative pre-mRNA splicing: factors involved in splice site selection. J Cell Sci 107:1-7.

O'Conner LT, Lauterborn JC, Gall CM, Smith MA (1994) Localization and alternative splicing of agrin mRNA in adult rat brain: transcripts encoding isoforms that aggregate acetylcholine receptors are not restricted to cholinergic regions. J Neurosci 14:1141-1152.

Patthy L (1991) Laminin A-related domains in crb protein of Drosophila and their possible role in epithelial polarization. FEBS Lett 289:99-101.

Patthy L, Nikolics K (1993) Functions of agrin and agrin-related proteins. Trends Neurosci 16:76-81.

Patthy L, Nikolics K (1994) Agrin-like proteins of the neuromuscular junction. Neurochem Int 24:301-316.

Reist NE, Werle MJ, McMahan UJ (1992) Agrin released by motor neurons induces the aggregation of acetylcholine receptors at neuromuscular junctions. Neuron 8:865-868.

Rio DC (1993) Splicing of pre-mRNA: mechanism, regulation and role in development. Curr Opin Cell Genet Dev 3:574-584.

Ruegg MA, Tsim KWK, Horton SE, Kroger S, Escher G, Gensch EM, McMahan UJ (1992) The agrin gene codes for a family of basal lamina proteins that differ in function and distribution. Neuron 8:691-699.

Rupp F, Payan DG, Magill-Solc C, Cowan DM, Scheller RH (1991) Structure and expression of a rat agrin. Neuron 6:811-823.

Rupp F, Ozcelik T, Linial M, Francke U, Scheller RH (1992) Structure and chromosomal localization of the mammalian agrin gene. J Neurosci 12:3535-3544.

Schell MJ, Danoff SK, Ross CA (1993) Inositol (1,4,5)-triphosphate 
receptor: characterization of neuron-specific alternative splicing in rat brain and peripheral tissues. Mol Brain Res 17:212-216.

Smith MA, O'Dowd DK (1994) Cell-specific regulation of agrin RNA splicing in the chick ciliary ganglion. Neuron 12:795-804.

Smith CW, Patton JG, Nadal-Ginard B (1989) Alternative splicing in the control of gene expression. Annu Rev Genet 23:527-577.

Stamm S, Casper D, Dinsmore J, Kaufmann CA, Brosius J, Helfman DM (1992) Clathrin light chain B: gene structure and neuron-specific splicing. Nucleic Acids Res 20:5097-5103.

Sugiyama J, Bowen DC, Hall ZW (1994) Dystroglycan binds nerve and muscle agrin. Neuron 13:103-115.

Tao-Cheng J-H, Nagy Z, Brightman MW (1990) Astrocytic orthogonal arrays of intramembranous particle assemblies are modulated by brain endothelial cells in vitro. J Neurocytol 19:143-153.
Thomas WS, O'Dowd DK, Smith MA (1993) Developmental expression and alternative splicing of chick agrin RNA. Dev Biol 158:523535.

Tsim KWK, Ruegg MA, Escher G, Kroger S, McMahan UJ (1992) cDNA that encodes active agrin. Neuron 8:677-689.

Wallace BG (1989) Agrin-induced specializations contain cytoplasmic, membrane, and extrcellular matrix-associated components of the postsynaptic apparatus. J Neurosci 9:1294-1302.

Wisden W, Morris BJ (1994) In situ hybridization with synthetic oligonucleotide probes. In: Biological techniques series, In situ hybridization protocols for the brain (Wisden W, Morris BJ, eds), pp 9-34. New York: Academic.

Yamada T, Goto I, Sakaki (1993) Neuron-specific splicing of the Alzheimer amyloid precursor protein gene in a mini-gene system. Biochem Biophys Res Commun 195:442-448. 